\title{
The Implications of Big Data and Social Media Analytics on Industry 4.0
}

\author{
Agus Rhesa Rudiansyah \\ Communication Science \\ University of Indonesia \\ Jakarta, Indonesia \\ ares.rudiansyah@gmail.com
}

\begin{abstract}
The world is now in the midst of a massive digital transformation. This transition was so great that the term Industry 4.0 rose to represent the fourth revolution that had occurred in various fields. The fourth industrial revolution continued what had begun in the third industrial revolution with automation and intelligently upgraded computerization through autonomous systems driven by data and machine learning. Because industry 4.0 is very consumer-centric, businesses are forced to innovate to satisfy and make consumers happy about their products. To did so, businesses turned to Big data and social media analytics. These new technologies are used by many companies from various industries such as manufacturing, logistics, and even by political figures to win elections. This article was written to explain the importance of using big data technology and social media analytics in the current industrial era 4.0.
\end{abstract}

Keywords - industry 4.0, big data, social media analytics, business, social media

\section{INTRODUCTION}

The world is now in the midst of a massive digital transformation. This transition was so great that the term Industry 4.0 rose to represent the fourth revolution that had occurred in various fields. The fourth industrial revolution continued what had begun in the third industrial revolution with automation and intelligently upgraded computerization through autonomous systems driven by data and machine learning. Because industry 4.0 is very consumer-centric, businesses are forced to innovate to satisfy and make consumers happy about their products. To did so, businesses turned to Big data and social media analytics. These new technologies are used by many companies from various industries such as manufacturing, logistics, and even by political figures to win elections.

Users spend more than $20 \%$ of their time online on social media sites. Facebook has a world market penetration rate of over 12\%; $50 \%$ in North America only. This number is growing rapidly, with Facebook alone reaching 2.38 billion users in 2019 [1]. Facebook's cellular usage is also growing faster, with an annual increase of $67 \%$ [1]. The amount of information seen during the day gives a more surprising indication of the enormous influence of social media. Nearly one billion active Facebook users collectively spend around 20,000 years online every day. In the same twenty-four hour period, YouTube has more than 4 billion views, totaling 500 years of video (spread among 800 million unique users), and 140 million active Twitter users sending more than 340 million tweets [1]. This figure is not just a passive use of social media. YouTube video analysis shows 100 million people take some kind of "social action" every week (with likes, dislikes, comments, etc.). This action doubled over a span of two years. Facebook has integrated social actions in its online advertising, for example by allowing users to see whether their friends like or vote on the advertised product. Likewise, hashtags on Twitter (and now other social media platforms) have given users another quick and easy way to express their likes, dislikes, interests and concerns, and this presents further opportunities (or challenges) for businesses that want to keep following this sentiment.

With a huge amount of data circulating on social media or big data, the technology that able to detect and analyze these data quickly or in real-time is needed. Social media analytics can fill the gap, companies can find out accurately what people are saying about their brands and products to take the next step using this technology.

The combination of big data and social media analytics has a huge impact on the transition from 4.0 to 5.0 that's happening. This article was written to describe the strengths and implications caused by the presence of big data and social media analytics for industry 4.0, especially in the communications industry.

\section{CONCEPTS AND THEORY}

\section{A. Big Data}

Big Data Analytics is the use of a large collection of data collected from within and outside the company. Utilizing such data sets is generally a very complex thing to do and using traditional processing applications may not be enough [2].

IBM breaks big data into four dimensions: volume, variety, velocity, and veracity. This was inspired by the original discussion of E-commerce in three dimensions, namely, volume, velocity, and veracity by Doug Laney, an analyst of META Group (now Gartner). Another V, which is Value (sometimes changing to validity or verification), can be added to IBM's 4V. Increasing volume (amount of data), velocity (speed of data entering and leaving), and variety (range of data types and sources) of big data are at the core of the challenges that must be answered [3]

\section{B. Social Media Analytics}

Until now, social media analytics, which is also called social media monitoring, has been defined by several practitioners and academics. However, there is no comprehensive definition. Crawford defines social media 
monitoring only as "paying attention online."[4] Based on Sponder, Töllinen et al. refer to social media monitoring as "a means to organize conversations on the internet in a structure that allows users to cut, browse, and see how conversations are interconnected in one holistic view."[5]

Given the fact that taking social media data may have no value for business, Maye suggests a new definition that enhances the previous definition by addressing the potential benefits of social media data for business purposes:

"Social media monitoring is the process of scanning social media to identify and analyze information about the company's external environment, to assimilate and utilize external intelligence obtained for business purposes."[6]

\section{Industry 4.0}

Industry 4.0 is a complex and flexible system that involves digital manufacturing technology, network communication technology, computer technology, automation technology, and many other fields. The basis of its implementation is based on digital design and simulation, production data management networks, and production process management, transforming the entire process into access to knowledge and laws on management, mining, analysis, assessment and decision making. Whereas on the other hand, Industry 4.0 is based on CPS, which relies on communication and control in close collaboration to achieve intelligent real-time sensing production systems, dynamic control, and information services using computing technology. Industry 4.0 key technologies mainly refer to CPS, mobile Internet and the Internet of things, cloud computing, big data, and sophisticated analytic technique [7].

\section{RESEARCH METHODOLOGY}

The method used in this research is descriptive qualitative research method. Qualitative research method is an approach to explore and understand the meaning of groups or individuals relating to human and social problems. Data is usually collected through data analysis inductively by building from specific themes to general themes that also involve questions. The researcher then makes an interpretation of the meaning of the data compiled. The final report is written in a flexible structure. Those who use this research method support how to view inductive research, the importance of structuring the complexity of the situation, and focus on individual meanings. [8]

\section{DISCUSSION AND FINDING}

\section{A. The Implications of Big Data and Social Media Analytics on Industry 4.0}

According to Global Manufacturing, simply put, big data will be very important for the fourth industrial revolution. In fact, some people say that big data is Industry 4.0, and industry 4.0 cannot be separated from big data. In manufacturing, for example, improvements and efficiencies in big data analysis are expected to bring billions of dollars to industry over the next five years.[9]

In addition to the emergence of big data in practical industries, the arrival of social media also opens up another potential of big data through social media analytics. Fan \& Gordon writes that companies, brands, or figures have to start paying attention to social media phenomenon because nowadays social networking is the most popular online activity. About $91 \%$ of adults use social media regularly, and Facebook, YouTube, and Twitter is the first, third, and tenth most accessed site on the Internet.[10]

Stieglitz et al state that there is a significant interest in analyzing data from social media for practical purposes. For example, in analyzing social media data, companies see opportunities to target advertising, PR, social customer relationship management (CRM), and business intelligence (BI). Specifically, the main interest behind the company's activities on social media is how to use it effectively as an additional channel for marketing.[11]

\section{B. The Case Study of Social Media Analytics Usage in Indonesia}

In Indonesia, opportunities for the use of social media analytics have begun to be applied to find out the image of politicians during the election period. This was obtained from the results of an interview with Raka Septian, one of the Data Engineers at Indonesia's big data analytic company, Paques.

Raka used his company's software, Pamedi (Paques Media Intelligence) to analyze the hype generated on Twitter for keyword "Ahmad Syaikhu" during the 2018 West Java Governor Election contest.

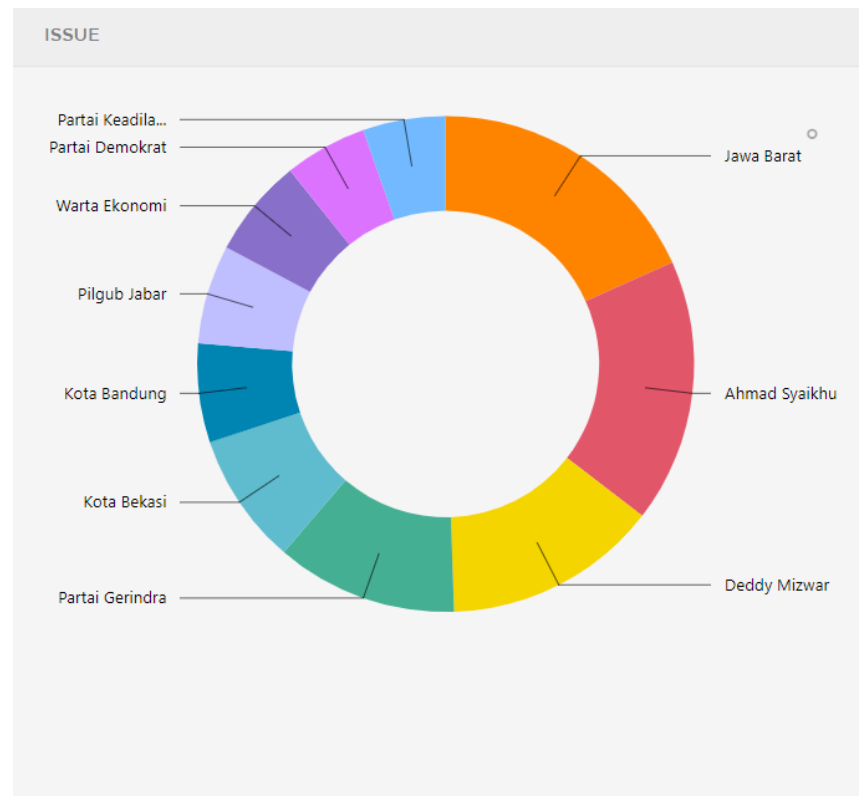

Fig. 1. Top Issues

The graph shows that issues related to Ahmad Syaikhu are dominated by reports about West Java which were most likely caused by the pool of prospective West Java governor candidates who was trending at the time. The name Deddy Mizwar also received a sizeable portion of the news regarding Ahmad Syaikhu. The rest was filled with news about several parties and the City of Bekasi, which at that time was led by Ahmad Syaikhu together with Rahmat Effendi. 


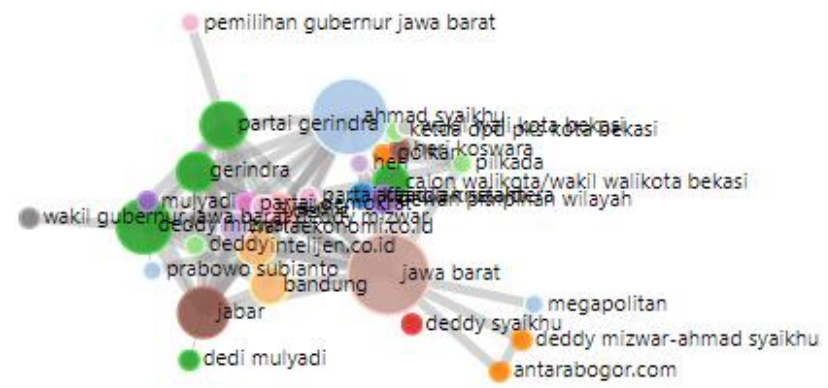

Fig. 2. Network Analysis

The coverage of Ahmad Syaikhu from the results of Network Analysis is still dominated by the coverage of the West Java Pilkada, where names such as Prabowo Subianto and Deddy Mizwar appear in this Network Analysis.

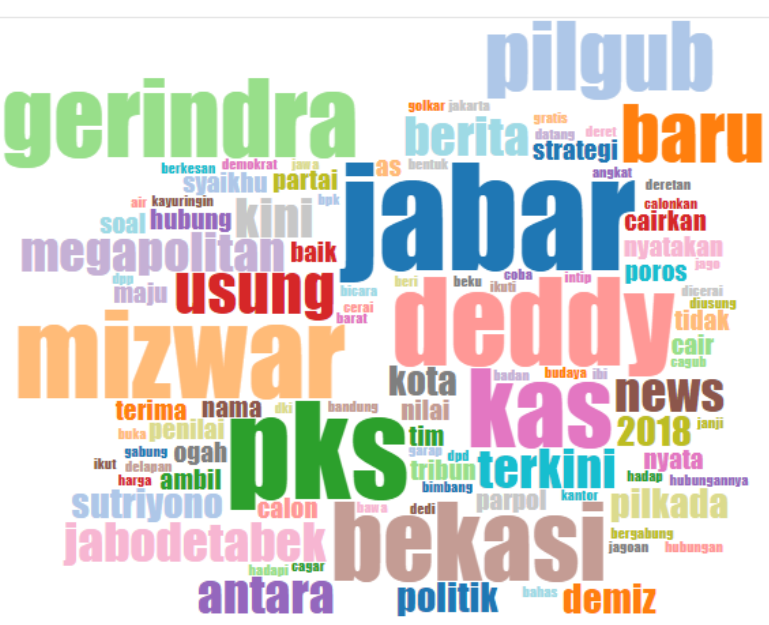

Fig. 3. Word Frequency Analysis

In the Word Frequency analysis, the portion of coverage related to West Java still dominates. This is related to the West Java Governor candidate discourse.

From the results of social media analysis conducted by social media analytics software, Raka as a Data Engineer was able to make predictions that Ahmad Syaikhu will most likely advance as a contestant in the 2018 Governor Election and affiliated with keywords such as Gerindra and Prabowo Subianto.

This prediction was proven true when Ahmad Syaikhu came forward as a candidate for Deputy Governor of West Java along with Sudrajat and was backed by the Gerindra Party.

\section{CONCLUSION}

The latest technology innovations, especially from the field of information technology led to the industrial revolution
4.0. This industry relies heavily on machine automation and digital technology continues to grow and there are no signs of slowing down. Two of the most emerging technologies in Industry 4.0 are big data and social media analytics.

Social media provides connections between social networks, personal information channels, and mass media. Social media data presents many new opportunities and challenges for information producers and consumers. The challenge is for companies to be able to analyze the large volume of unstructured text data created by users to gain meaningful insights about opinions, issues discussed, sentiments and trending topics. This has become possible with the presence of social media analytic, this big data derivative technology is able to analyze data on social media to find out sentiments towards a brand or even a political figure.

Industry 4.0 era presents opportunities and challenges in the present as well as in the future, companies that can adapt and accept radical changes in business technology will be survivors in this industry. Big data and social media analytics are only two of the many tools that can be used to survive in industry 4.0, and any company that is able to maximize these two technologies for their interests will surely be left behind by anyone who is afraid of change.

\section{REFERENCES}

[1] A. Hutchinson, "Facebook Reaches 238 Billion Users Beats Revenue Estimates in Latest Update," Social Media Today, 2019. https://www.socialmediatoday.com/news/facebook-reaches-238billion-users-beats-revenue-estimates-in-latest-upda/553403/ (accessed May 20, 2019).

[2] B. Nicoletti, The Future of FinTech. 2017.

[3] O. Kaynak and S. Yin, "Big Data for Modern Industry: Challenges and Trends [Point of View]," Proc. IEEE, vol. 103, pp. 143-146, 2015, doi: 10.1109/JPROC.2015.2388958.

[4] K. Crawford, "Following You-Disciplines of Listening in Social Media," Contin. Media Cult. Stud. - Contin. MEDIA CULT STUD, vol. 23, pp. 525-535, Aug. 2009, doi: 10.1080/10304310903003270.

[5] J. Mero, T. Aarne, H. Karjaluoto, and C. Jayawardhena, "Digital and social media marketing usage in B2B industrial section," Mark. Manag. J., vol. 22, pp. 102-117, Jan. 2012

[6] M. Mayeh, R. Scheepers, and M. Valos, "Understanding the role of social media monitoring in generating external intelligence," ACIS 2012 Proc. 23rd Australas. Conf. Inf. Syst., Jan. 2012.

[7] K. Zhou, T. Liu, and L. Zhou, "Industry 4.0: Towards future industrial opportunities and challenges," in 2015 12th International Conference on Fuzzy Systems and Knowledge Discovery (FSKD), 2015, pp. $2147-$ 2152 .

[8] J. W. Creswell, Research Design: Qualitative, Quantitative, and Mixed Methods Approaches. SAGE Publications, 2014.

[9] R. Dagge, "Big data is the fourth industrial revolution," Manufacturing Global, 2016. https://www.manufacturingglobal.com/technology/bigdata-fourth-industrial-revolution (accessed May 20, 2019).

[10] W. Fan and M. Gordon, "The Power of Social Media Analytics," Commun. ACM, vol. 57, pp. 74-81, Jun. 2014, doi: 10.1145/2602574.

[11] S. Stieglitz, L. Dang-Xuan, A. Bruns, and C. Neuberger, "Social Media Analytics: An Interdisciplinary Approach and Its Implications for Information Systems," Bus. Inf. Syst. Eng., vol. Forthcoming, Jan. 2014, doi: 10.1007/s11576-014-0407-5. 